\title{
Developing a Sustainable Mobility Plan in Piraeus with Special Emphasis on Cycling
}

\author{
Efthimios Bakogiannis, Avgi Vassi, Maria Siti and Georgia Christodoulopoulou \\ Department of Geography and Regional Planning, National Technical University of Athens, 9 Iroon Polytechniou, Zografou Campus, \\ Athens 157 80, Greece
}

\begin{abstract}
Sustainable mobility planning is an emerging planning concept, largely applied in European and American cities during the last two decades, as a means to achieve more efficient and sustainable cities regarding the ceasing of the major threats to urban environment, namely: climate change, accidents, traffic saturation, air and noise pollution, car dependency and domination in the public space. Municipality of Piraeus is a developing autonomous commercial and business center, characterized by high density housing, narrow street geometric characteristics and the port presence. Aim of this paper is to present its recent sustainable mobility plan by putting special emphasis on the strategic plan for a cycling network. The key principles of its methodological development are demonstrated along with the strategic enhancement of walking and multimodal transport services. The main objective is to integrate cycling in mobility policies applied by the described plan in Piraeus.
\end{abstract}

Key words: Sustainable mobility plan, Piraeus, bicycle planning, walkability.

\section{Introduction}

During the 20th century, planners were focused on the development of cities. Eventually, it was revealed that this model was not sustainable and it was not possible to continue in that way. During the first decade of the 21 st century, the world decided that sustainability is something urgent that should affect all the aspects of our lives. The growing need for sustainability (in terms of economy, environment and society) leads the cities to adopt mobility solutions that were neglected all these years. The promotion of cycling, walking and public transport became the core of mobility management policies.

Cycling is an old but fast growing component of European cities' mobility planning schemes. Cycling has strategic importance for the sustainable development of European cities. Many European projects have been dealing with its promotion (MOMENTUM (Mobility Management for the Urban Environment), MOSAIC

Corresponding author: Maria Siti, Ph.D. candidate, research fields: transportation planning, sustainable mobility, traffic management and cycling urbanism.
(Mobility Strategy Applications in the Community), MAX (Successful Travel Awareness Campaigns and Mobility Management Strategies), EPOMM (European Platform on Mobility Management), OBIS (Optimising Bike Sharing in European Cities), CIVITAS (City, Vitality and Sustainability), etc.). The Interreg IVC CycleCities Project [1] co-financed by ERDF (European Regional Development Fund) aims at building and sharing knowledge among European cities. It facilitates good practice transfer and experience exchange on the integration of cycling into urban mobility management schemes. It specifically aims to exchange experiences and make transferable good practices on mobility management and cycling. It has as an objective to establish consensus on policies towards sustainable European mobility management schemes and to establish an European, multilingual, freely-accessible knowledge and experience base. It also enhances the awareness on the integration of cycling in urban mobility management schemes. CycleCities Project addresses some critical challenges and opportunities for cities that relate to a number of factors. 
Traffic congestion is that one of them as $30 \%$ of car trips in Europe are under $3 \mathrm{~km}$ and $50 \%$ are under $5 \mathrm{~km}$ which is a 15 minute bike ride [2]. Reducing car use and increasing the share of public transport, walking and cycling will unclog roads and reduce congestion and associated delays, lost working hours and wasted fuel. Private motorized transport also imposes high costs on individuals and society, both directly (road construction and maintenance) and indirectly (casualties, obesity, pollution, congestion, etc.). The European Commission [3] estimates the external costs of road transport (mostly individual motorized transport) at $2.6 \%$ of GDP (gross domestic product). Other studies suggest as much as $4 \%$ and $8 \%$. The shift from car towards sustainable means of transport provides an opportunity for huge cost savings. Regarding the carbon footprint, $40 \%$ of Europe's $\mathrm{CO}_{2}$ emissions from road transport and $70 \%$ of other pollutants are due to urban traffic. As recognized in EU Communication 2009/279, urban transport accounts for $40 \%$ of $\mathrm{CO}_{2}$ emissions, and $70 \%$ of other air pollution, in particular PM10 and $\mathrm{NO}_{\mathrm{x}}$ emissions, from transport. Tripling the modal share of cycling, for example, would save $5 \%$ of transport $\mathrm{CO}_{2}$ emissions by 2020. This would make a significant contribution to mitigating climate change and decreasing dependency on fossil fuels.

Increasing the modal share of walking and cycling enhances physical and mental health. Accidents involving cars are associated with cycling and walking, too. Nevertheless, the benefits to life expectancy of choosing to cycle are 20 times the injury risks incurred by that choice [4]. Higher proportions of commuter cyclists are linked with lower risks of casualties. Car drivers are used to the presence of cyclists and are more likely to be cyclists themselves. The increased uptake of sustainable means of transport leads to reduced land consumption: 10 bikes can be parked in the space required for one car. One lane of typical road can accommodate 2,000 cars per hour, or 14,000 bikes. CycleCities Project also targets fostering of investment and neighborhood revitalization through enhancing sustainable means, as friendly cities attract individuals and businesses investment, encourage neighborhood revitalization and can improve a city's quality of life.

Piraeus is one of the cases of cities that was developed according to the plans for the car. Piraeus is a typical Greek city. The streets are not pleasant and the movement of pedestrians and cyclists is not safe. The sidewalks are too narrow and full of obstacles, forcing pedestrians to walk on the road. There is absolutely no infrastructure for the cyclists. The above mentioned characteristics in combination with the absence of greenery turn the roads into polluted and noisy corridors (known in the literature as a canyon effect). The whole environment is not at all attractive to walk or even stand in the road. Walking and cycling are not an option, and as a result, residents are strongly depended on their car or motorcycle. Regarding public transport, although there is a good connection between Piraeus and Athens, there are several service gaps in the municipal neighborhoods. CycleCities Project gave Piraeus the opportunity to develop a sustainable mobility plan with a specific focus on cycling.

The methodology followed, was based on the structure defined by CycleCities Project, but some procedural steps were modified in order to match the need and desires of the specific municipality. The starting point was the analysis of the current situation of the municipality. In the next phase, the problems were detected and the ways to be addressed were defined. Finally, solutions were prepared, that concerned improving the accessibility of pedestrians in specific areas, enhancing cycling and improving public transport.

\section{Methodology}

It has been identified that European cities have the knowledge and experience on policies and projects, when at the same time other European cities are lagging behind. INTERREG IVC provides funding for interregional cooperation across Europe enabling the exchange of knowledge and practices. CycleCities 
Project, as part of INTERREG IVC, aims to strengthen the cohesion policy of Europe. CycleCities Project collected good practices of cycling and mobility management policies in Europe related to land use planning, cities' successful mobility management strategies, cases of cities' participation strategies for reshaping urban mobility and best architectural designs of cycling infrastructures. The cases collected have resulted in the development of good practice guides. A main outcome of this project was the "cycling implementation plan" conducted by each partner. The plans integrated the outcomes of the research work done. They combined the results from the good practices but also the outputs of the research on cycling in mobility management strategies for sustainable transport: evidence-based analysis of traffic trends, needs, deadlocks, controversies, regulations and policies, on infrastructures for cycling and on the environmental and economic gains and costs.

The steps followed were predefined from the methodology developed by the CycleCities consortium that allowed possible adjustments to local realities. The plan described in this paper demanded an in-depth analysis of the existing situation and a strong support from the participatory procedures, as Piraeus was considered a "beginner" not only in cycling but in sustainable mobility. In our study, the principal aim was to propose a plan, adapted to the social and physical features of the City of Piraeus. Along with the exploration and analysis of the existing situation, we used a bottom-up approach that involved residents and visitors of the City of Piraeus, not only by integrating their views and desires for the city but also by encouraging them to choose among alternative mobility policy solutions [5]. The methodology used during the planning procedure is shown in Fig. 1.

As it is shown in Fig. 1, the procedure was held in four successive stages:

(1) In the first stage, our objective was to explore the existing situation regarding mobility issues and collect qualitative and quantitative data that would allow us to understand the image and function of the city. Simultaneously, a qualitative approach was chosen as a participatory process and interviews were conducted in order to detect the critical mobility issues through the perspective of Piraeus' residents;

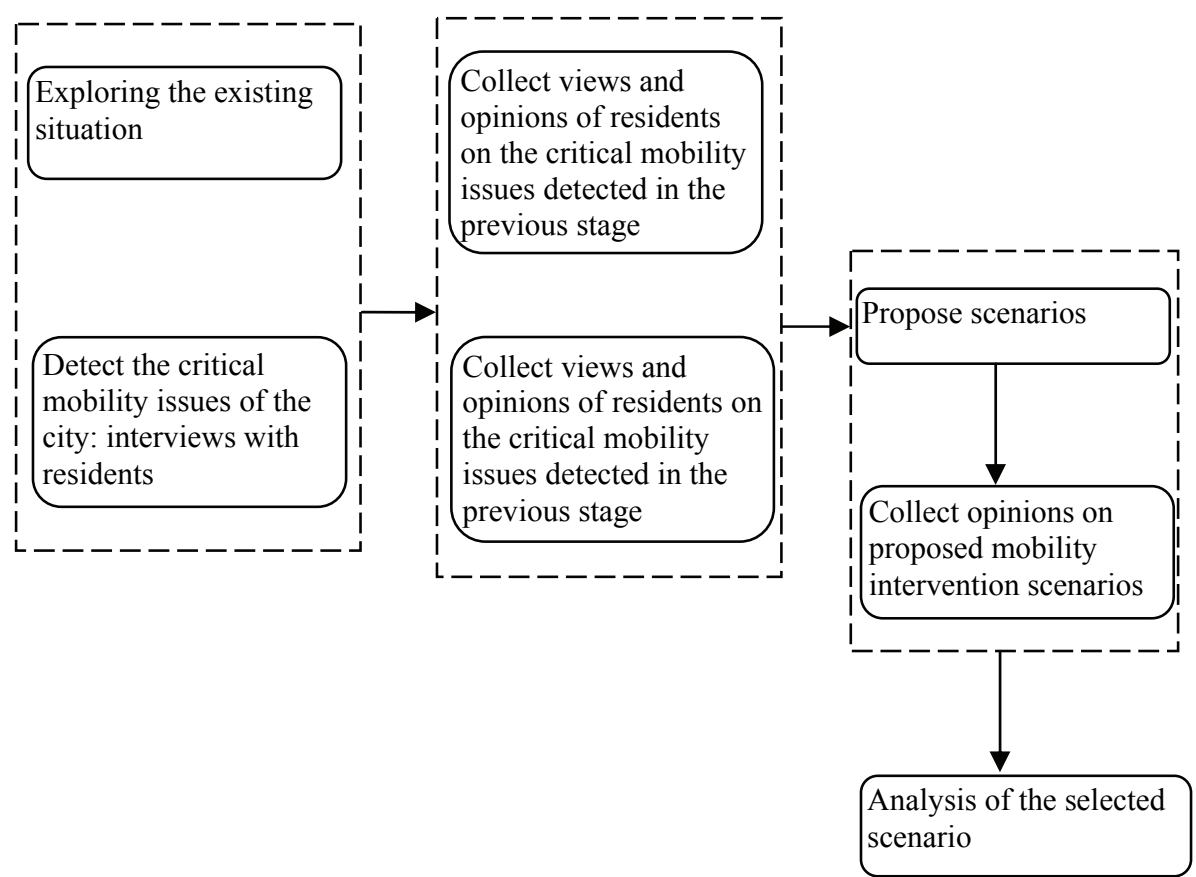

Fig. 1 Description of the methodology used in the planning procedure. 
(2) During the second stage, the analysis of the existing situation took place. Through the results from the interviews (first stage), we were able to elaborate a questionnaire that collected views and opinions of residents on the critical mobility issues detected;

(3) The third stage consisted of two steps: At first, based on the outcomes of the questionnaire and of the findings of the analysis of the existing situation, different scenarios were proposed. The scenarios represented each of the "possible futures of the city", based on mobility choices; The second step concerned a second questionnaire. This one referred not only to residents, but also to visitors and concerned actual sustainable mobility dilemmas resulted from the scenarios. At the same time, the municipality and the stakeholders were informed about the results of the previous steps and about the mobility scenarios;

(4) Finally, the most desired scenario based on the outcomes of the questionnaire and through the participation of residents, visitors, the municipality and stakeholders, was selected and analyzed.

In the following sections, the analysis and the selected scenario are described.

\section{Exploring the Current Situation in the Municipality of Piraeus}

\subsection{Overall Urban Fabric Elements and Future} Transportation Infrastructure in Piraeus

Piraeus is a historic Greek city, built according to orthogonal grid system (Hippodamian planning style), that has important archaeological sites and a large identical waterfront, mostly utilized for leisure and recreational purposes. It includes critical and supra-local attraction nodes, such as the Port of Piraeus, a number of businesses and services as well as a vivid coastal zone. Due to its industrial character and port location, it has attracted numerous shipping, logistics and trade facilities. The city is characterized by high density housing, inadequate street network, lack of public green areas and a variety of geographical features ranging from flat areas to high terrain. The study has examined the attraction nodes of the city (Fig. 2) and the wider region, the topography, the statutory and implemented land uses, spatial disruptions and places of social exclusion, geometric characteristics of the street network and the overall urban fabric, the presence of public spaces and other features that have shaped the current urban streetscape. Special attention was given to the existing urban disruptions developed by land use zoning (i.e., industrial, shipping and trade zones separating the city from the waterfront) and the lack of social cohesion, which was apparent in the contradictions between the low income areas north of Kondili Coast and high income ones located near Piraiki Peninsula.

From the observations of Piraeus urban evolution during the last 50 years, the study can summarize the following:

(1) Urban population was doubled from 1961 to 2001;

(2) Rapid and in cases uncontrolled urbanization has seriously affected the traffic conditions, parking amenities, level of travel services and the overall quality of life;

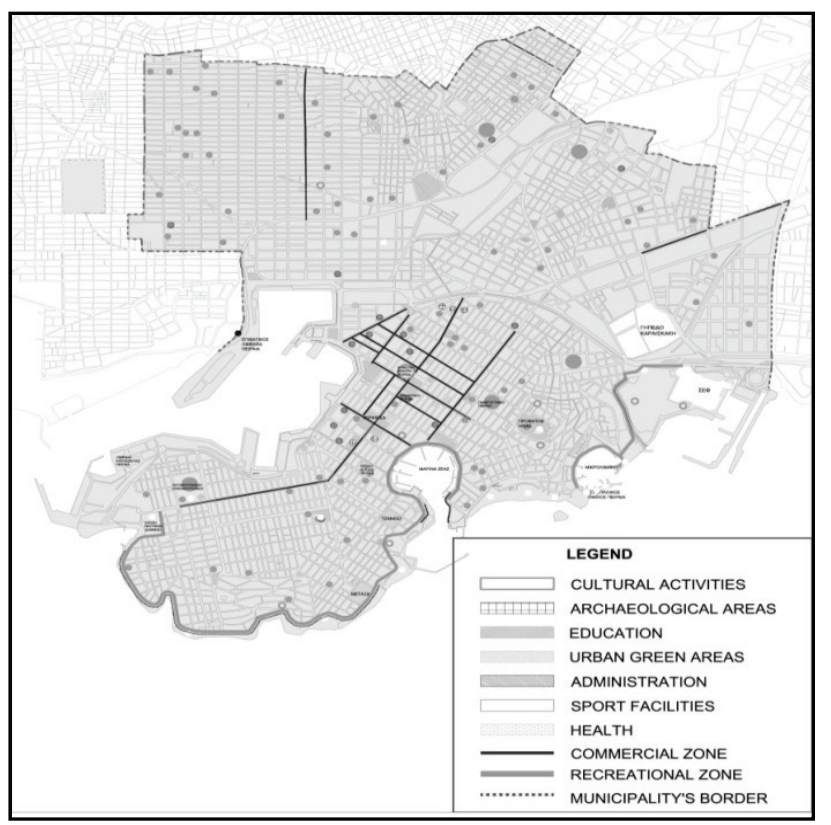

Fig. 2 Attraction nodes in the Municipality of Piraeus. 
(3) Social fabric has been altered by the high concentration of mostly low income population as well as of medium and high income residents;

(4) The number of trade and service activities were constantly increasing turning the city into a trade hub;

(5) The attraction of supra-local/metropolitan activities in the city centre has shaped and characterized the urban fabric.

This rapid urbanization had also a crucial impact on the sprawl of the main urban operations, either in punctual or linear forms around primary and secondary street arteries. During these alterations, estate values were rapidly increasing which has led to the replacement of the old building stock with modern high density buildings to accommodate this demand. It should be noted that $80 \%$ of buildings in 2011 were reported as high-rise with only the remaining $20 \%$ being one to two-storey buildings [6].

These mutations have altered the traditional character of the old city centre and its neighborhoods, while the waterfront was steadily evolving into a dynamic and attractive zone. Piraeus is now being shaped into a new metropolitan port city with the introduction of many productive activities of the tertiary economic sector, while manufacturing crafts and factories that were dependent to the old port character are disappearing. The location and readability of Piraeus morphology is highly outlined by its main highways and the coastal alignment. However, road and rail infrastructure penetrate the urban fabric and disrupt urban cohesion.

The strong and potential elements in the aforementioned fabric are the: port hinterland area, area of Freatida, transportation hub that accommodates the subway and the suburban railway, existing waterfront and its recreational routes, Peace and Friendship Stadium and its surroundings, Pireos Street and its historic alignment, Municipal Theatre and its adjacent square and the old market.

In planning terms, Piraeus has an up-to-date strategic development plan which attempts to address some of the identified deficiencies, without though achieving quick satisfactory results for a number of reasons, mostly related to long lasting permission processes and lack of concise monitoring procedures. Indeed, encouraging elements can be revealed through one of its latest proposals to conduct a plan for integrated urban intervention regarding the upgrade of four particularly deprived areas and the enhancement of its two important economic sections, namely shipping and tourism.

\subsection{Traffic Characteristics and the Potential for Cycling}

Piraeus presents a downgraded street environment due to a number of reasons. Congestion appears in most primary and secondary roads while illegal parking tends to be the norm. Travel needs are increasing and the port's presence stresses further traffic around the port hinterland area. Being a dense city that is highly car dependent as well as its relation with the wider Athenian conurbation, develops a congested environment with various limitations in mobility choices. The upcoming public transportation works (i.e., metro and tram expansion) are expecting to alter significantly Piraeus placement in the regional setting, as it is becoming a focal node and a port city in the European context.

The analysis of the current traffic situation in Piraeus has examined the following factors in order to identify the potential implementation of an alternative mobility behavior and the integration of cycling in transportation choices: traffic volumes on major roads, poles of attraction, parking conditions, geometry of the arterial network of secondary roads, existing hierarchy of roads, existing one-way roads, speed limits, bus network, rail network and the coverage areas of the fixed rail, main pedestrian routes, existing bicycle network (if available), main bicycle routes and the cycling network of the wider area (e.g., metropolitan cycling network in Athens).

Results have shown that most of the primary and 
secondary streets lack adequate geometrical characteristics; Street surface conditions are poor and most importantly, traffic is highly affected by illegal on-street parking many times in both directions; Adding to this, railway network is crossing the street network in a number of cases. The average travel speed is $17 \mathrm{~km} / \mathrm{h}$, which falls to $8 \mathrm{~km} / \mathrm{h}$ in peak hours. Given the current situation, predictions say that the average travel speed is going to be decreased to $11 \mathrm{~km} / \mathrm{h}$, which reveals the need for an immediate alteration in travel behaviors. Parking conditions have slightly been improved due to the building of the two underground parking stations, though the demand remains extremely higher due to the large amount of visitors and the fact that most of the old buildings lack private parking facilities. The circulation of large trucks and lorries travelling to and from the port complicates traffic further. Systematic traffic transgressions is a common cause for many delays, which if combined with poor geometry and lack of pedestrian and cycling network, creates a downgraded urban streetscape.

Accidents, saturation, pollution, noise, cityscape distortion are some of the many disadvantages of the current image. Car domination is costly, unhealthy and deteriorates Piraeus viability.

The potential introduction of cycling in such environments can impact largely with the following benefits with their relevant parameters [1]:

(1) environmental benefits:

- energy use;

- greenhouse gases/air quality;

- quality of urban spaces;

(2) transportation benefits:

- time costs;

- congestion;

- vehicle operating costs;

- transit synergies;

- infrastructure and maintenance costs;

(3) health benefits:

- physical fitness;

- air pollution;
- noise pollution;

(4) safety:

- traffic accidents per transportation mode and distance;

(5) cycling tourism:

- cycling holidays and day trips by cycle/employment;

(6) sports and leisure:

- cycling events;

(7) cycling industry.

Design, manufacture, retail, rental and maintenance of bicycles, components and equipment, bicycle sharing systems, bicycle parking facilities, etc.

The benefits can also be categorized into those for citizens, those for the general public policy, those for developers, etc. A recently published guide [7] outlines public policy benefits regarding: increased productivity of local companies raising more taxes, healthcare costs are reduced, increased access to public transport infrastructure, reduced costs for maintaining roads and car parks, reduced crime as more eyes and ears are on the streets and reduced collisions. Moreover, interesting features are revealed for developers, which benefits can be important in a growing centre like Piraeus, including the following key aspects:

- Cycling requires a smaller area of land per capita: the need for wide roads and large car parks is reduced;

- It facilitates higher densities without overcrowding: Houses need less car parking;

- The impact of external traffic impact is reduced: Less opposition from surrounding settlements worried about high volumes of car traffic and the noise and pollution that this brings;

- It is a place and community where people want to live: safe, family-friendly, accessible, peaceful;

- It is easier to gain approval from planning authorities: strong fit with public policy objectives;

- It is easier to achieve conformance with NPPF (National Planning Policy Framework) [8]: The principles outlined in this guide are strongly in line with NPPF Section 4: Promoting Sustainable Transport. 
Indeed, cycling enhancement in areas where no similar plans have ever been applied should be a part of a wider vision integrated to an overall sustainable mobility plan. In the European context, cycling presents strategic importance for the future of transport planning and the sustainable development of cities. In The Mayor's Vision for Cycling in London [9], it is emphasized that cycling should become a normal part of everyday life, a common mode of transportation. A key priority in car dominated areas, like Piraeus, should be to "normalize" cycling, making it something anyone feels comfortable doing. A supporting theory to that, which has been transferred through numerous concepts and notions in the academy, is the transformation of the main streets of the area into "complete streets", in other words, streets are designed for everyone and include everyone, like pedestrians, cyclists, motorists and transit riders of all ages and abilities. Piraeus street network presents rather opposite design principles, as it is designed to accommodate mostly cars and in some cases, pedestrians.

\section{Configuring the Strategy for a Sustainable Mobility Plan-The Cycling Network}

\subsection{Sustainable Mobility Plan of Piraeus, Parallel Actions for the Development of the SM Plan}

The key pillars of sustainable mobility plan, as a concept, are public transportation, walking and cycling, which are highly connected to the presence of public spaces, the urban green, the upgraded street aesthetics, as well as traffic and parking management, all coherent with the capacity of the urban environment and the distribution of land uses. After all, Newman and Kenworthy [10] argued that one of the things that influences the travel choices is the urban form. Additionally, Milakis [11] points out the need for having integrated urban and transport planning, as land use policies can constitute an effective tool for changing travel behavior, which is also dependent on socio-economic parameters.

The sustainable mobility plan aims at "improving accessibility of urban areas and providing high-quality and sustainable mobility and transport to, through and within the urban area" [3]. Such plans use the integrated planning as a tool to achieve the functional city, the human city. Transport policies, infrastructures and measures define the accessibility level, cluster economic activities and affect the environmental quality of urban areas. At the same time, land use policies and interventions have an effect on transport modes and journey lengths in urban settings and therefore, when combined with effective public transport services and infrastructures for soft transport (walking, cycling), they can greatly contribute to sustainable urban mobility.

The previous steps of the methodology included the analysis of the current urban, traffic and environmental conditions as well as the first phase of the public consultation procedure. The key proposals of the implemented methodology are: infrastructure and policies planning, internal organization of the municipal administration, increasing awareness and public participation and meeting the requirements for environmental and economic sustainability, as well as social equity and health.

Regarding the infrastructure planning process, several good practices were examined and transferred in the context of the CycleCities Project. The main intervention pillars included the following aspects: development of traffic calmed areas, configuration of future green corridors, pedestrian network, cycling network and connectivity with neighboring areas, traffic management, tram extension, enhanced bus network and suggestions for further information and awareness.

The development of traffic calmed areas is an area-wide approach, which refers to engineering measures (i.e., speed bumps, chicanes, elevates crosswalks, curb extensions, medians, etc.) and strategies (i.e., $30 \mathrm{~km} / \mathrm{h}$ zone, "low traffic street" declaration, awareness raising, etc.) in order to reduce driving speeds, air and noise pollution and create a 
safe and friendly pedestrian environment. In the case of Piraeus, traffic calmed areas were also proposed as a means to reduce the volume of "through traffic" on local streets. NCCHPP (National Collaborating Center for Healthy Public Policy) [12] summarizes the following six main mechanisms commonly used to influence road safety and enhance public health:

(1) reduction of vehicle speeds;

(2) speed homogenization;

(3) reduction of motorized traffic volume;

(4) reduction of the number of points of conflict;

(5) improvement of visibility and reduction of exposure;

(6) increase driver alertness.

The selected areas (Fig. 3) were expanding within a 200-meter radius from public transportation stations and around the main streets of the city centre. Moreover, areas included several other nodes of important activities (business, leisure and commercial). Similar measures were also proposed in a 100-meter radius areas around schools and hospitals.

The development of green corridor routes aims at connecting the main attraction poles of the municipality with a parallel enhancement of the waterfront zone. Green addition in already shopping streets will strengthen commercial activity and allow them to become visiting places, while urban furniture regeneration will increase social cohesion in the surpassing areas. Proposals included five new green corridors expanding in a large area of the municipality, which could work as rewarding patterns for further greening. These corridors are linking several neighborhoods, public transport stations, school facilities as well as major open and public squares and parks.

Crucial interventions are also proposed through the development of a robust and cohesive pedestrian network, following the paradigms of various European city centers. Among the various benefits of this scheme, the increase in commercial activity is also expected. The extended pedestrianisation of the city centre along with the proposed traffic calmed areas demanded a

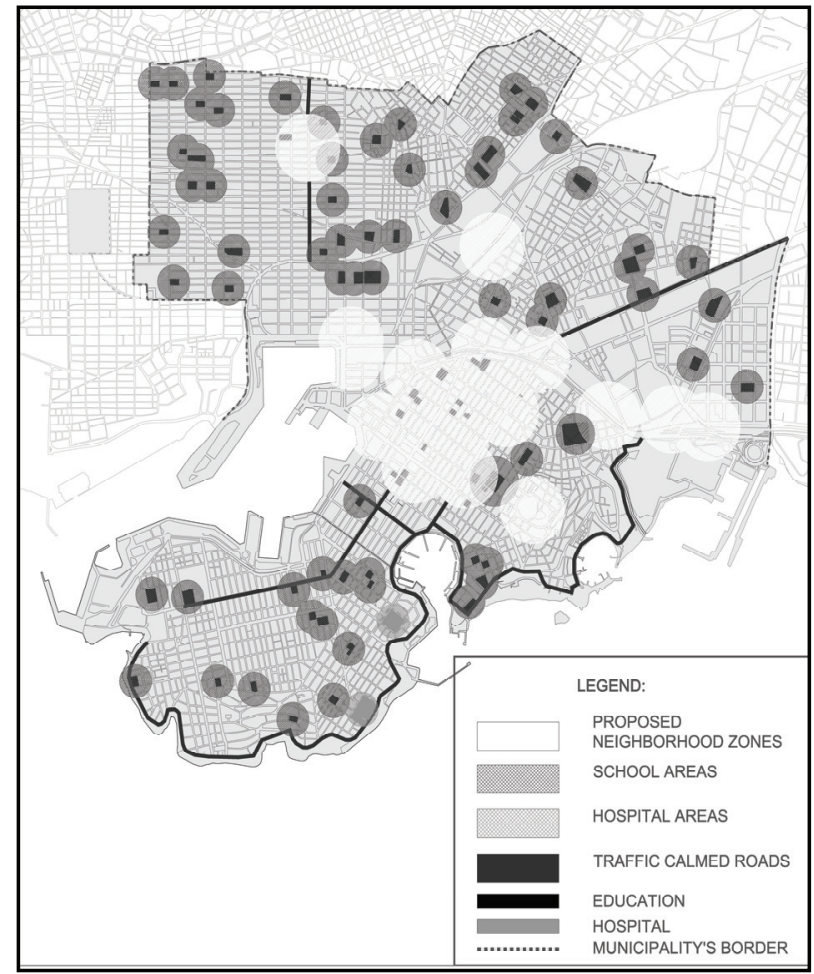

Fig. 3 Proposed traffic calmed areas plan in Piraeus.

complete traffic management program and an advanced approach in street hierarchy. Traffic direction in several sections is changing while several two-way streets are converted to one-ways. A system of local ring roads will assist the city centre to carry the needed traffic volumes, and most importantly, the result of the wider strategy will lead to less car-dependent mobility patterns.

The proposed cycling network will combine routes approved for metropolitan service through the metropolitan cycling network as well as local connections to the various activities (see next section).

Another complementary intervention suggests the extension of the tram network, which is already expanding from Athens city centre to Piraeus and additional bus services. The proposed new tram route would link the peninsula and the city centre as well as all the key metro and subway stations. The enhancement of the bus network includes the introduction of four new bus routes which would serve travels between residential areas and transportation hubs. 


\subsection{Strategic Plan for the Development of Cycling} Network

Piraeus, being a typical Greek city, has to go under major interventions in order to accommodate a modern and efficient cycling network, which could be an integral part of the overall transport network. The change in mobility priorities along with a coherent awareness raising campaign will assist in the development of expanded network for cyclists both in the city centre and the neighborhoods. Bicycle integration requires a city that is pleasant, safe and offers specialized spaces for moving and vehicle parking. Cyclists need dedicated spaces in primary and secondary streets while traffic calmed conditions can ease traffic in tertiary streets and local paths. Fundamental principles of the network are: safety, comfort and immediacy of activities. The whole plan is not simply aiming at fitting into the existing street network but rather change priorities of mobility, so particular attention has been paid to the integration of routes with a high quality urban architectural environment. The study on the cycling network derives from the priorities set and the lessons learned by the CycleCities Project. Its key principles have been developed in accordance to the good practice guides and the regional implementation plan for Piraeus.

The proposals indicate a double approach in cycling enhancement as they deal with connecting the city of Piraeus with the metropolitan cycling network of Attica and creating a cycle-friendly environment in the city itself.

The metropolitan cycling network of Athens/Attica is a strategic statutory plan, recently adopted by the Regulatory Master Plan for Athens-Attica 2021 [13], which is a $226-\mathrm{km}$ network with 36 fast lane routes that aspire to run through complex urban forms and inclined terrain, that could alter the whole approach of mobility in the wider area of Athens and Attica region. The plan is determined to be implemented through two main phases and will connect universities, recreational activities, cultural areas and sport facilities, shopping malls, open spaces, public transportation stations and many more.

In the case of Piraeus, the designed fast lane routes (in deep dark of Fig. 4) will cross most high avenues and waterfront arteries, linking the centre with neighborhoods and nearby suburbs.

A local cycling network will act complementary to the metropolitan and will connect the fast lanes with local routes in Piraeus neighborhoods. Proper selection of the key track routes has encountered a number of factors including location of focal activities and facilities, public opinion, inter-modal connectivity, terrain and regeneration potential. The key development areas will be Piraiki Peninsula with the main routes connecting the waterfront, the commercial centre of the city with cycle lanes surpassing most central thoroughfares and leading to most of the neighborhoods. Cycle lanes follow the neat city grid while mostly avoid high terrain (Fig. 4 and Table 1).

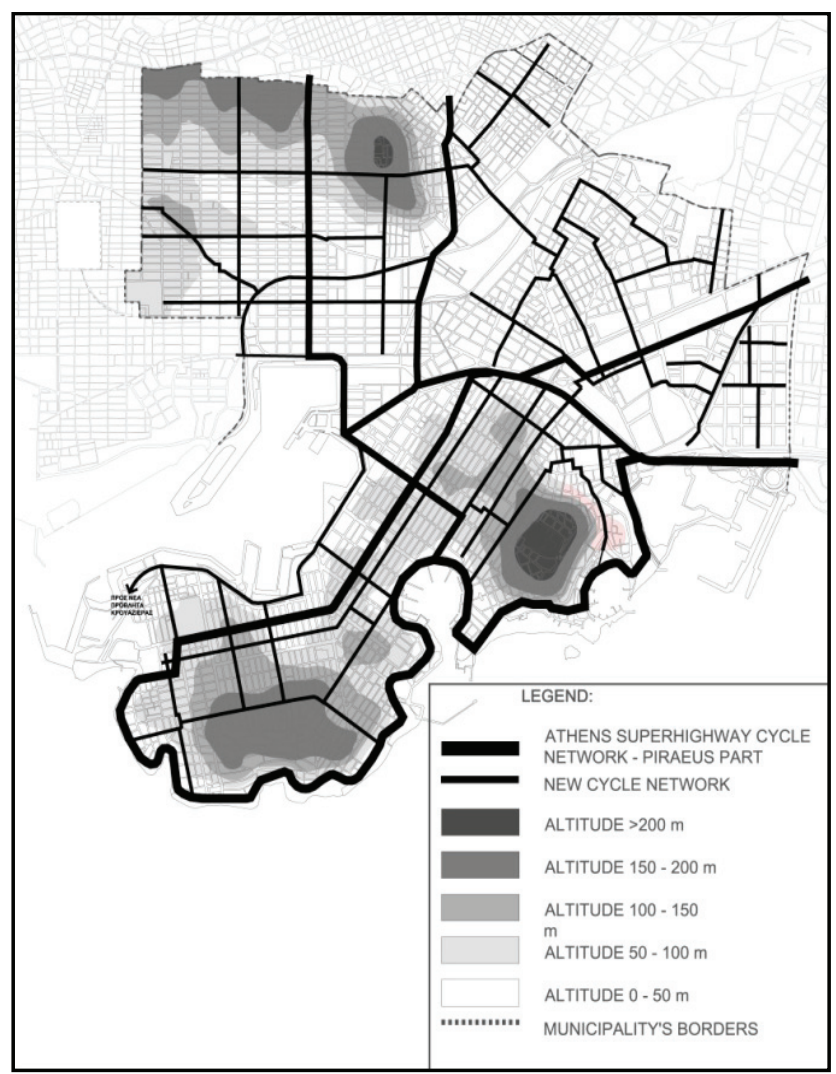

Fig. 4 The proposed local cycling network at Piraiki Peninsula. 
Table 1 Key elements and quantity of objects for bike sharing operation system in Piraeus.

\begin{tabular}{ll}
\hline Type & Quantity \\
\hline $\begin{array}{l}\text { Supply of electronically assisted kiosks for } \\
\text { bike parking_-stations }\end{array}$ & 12 \\
$\begin{array}{l}\text { Specially designed bikes, smart bikes, etc. } \\
\text { Software control user with a minimum of 5 }\end{array}$ & 240 \\
$\begin{array}{l}\text { user licenses } \\
\text { Bike parking }\end{array}$ & - \\
\hline
\end{tabular}

Apart from the local network and the metropolitan cycle lanes, the study is providing three additional and direct fast lane connections to the neighboring municipalities.

\section{Bike Sharing}

The most valid and widely used definition for a BSS (bike sharing system) is the following: "bike sharing scheme is a self-service, short-term, one-way-capable bike rental offer in public spaces, for several target groups, with network characteristics" (Optimising Bike Sharing in European Cities 1 dictionary). The principle of bike sharing is to offer a short-term access to bicycles on an "as-needed" basis without the costs and responsibilities of bike ownership. Shaheen et al. [14] summarize the benefits of bike sharing as flexible mobility, emission reductions, physical activity benefits, reduced congestion and fuel use, individual financial savings and support for multimodal transport connections. Nowadays, BSS are widely known as the last five years "bike sharing has experienced the fastest growth of any mode of transport in the history of the planet" [15]. The introduction of a BSS has profound impact on "creating a larger cycling population, increasing transit use, decreasing greenhouse gases, and improving public health" as reported by DeMaio [16].

The BSS has been designed (as part of the cycling network development) according to several principles applied in similar schemes, regarding its autonomy, utilization, user safety, equipment security and many more.

For the development of the scheme as well as its phasing process of implementation, researchers have considered various good practices from the international environment as well as encountered the specific needs and potentials of Piraeus Municipality. Its specifications followed the fourth generation bike sharing features. The BSS should be able to serve subscribers and visitors with a prepaid card or with the use of a visa card.

The key elements for its basic operation are the kiosks, bicycles, software and bike parking facilities (Table 1).

Research has evaluated a number of other factors in terms of its functions and has outlined the key features for:

- the communicating interface with the public (language, registration, guidance, locking-unlocking, real-time data of availability, safety of transactions, etc.);

- user service points;

- geometrical characteristics of all operational elements of the system (stations, bikes, etc.), energy options, charging needs;

- operational standards (average daily travels, speed limits and brakes requirements;

- interconnection of stations;

- GPRS (general packet radio service) support;

- its potential expansion;

- cost and investor's scheme.

Moreover, it should be noted that the research team has encountered a number of principles in order for the system to be successful, such as the following:

- There must be a continuous political support of the project in order to convince people to use it;

- The system should be reliable, i.e., enough bikes at stations, efficient maintenance, accompanying electronic means (applications), etc.;

- It is legitimate to find a (private) sponsor for the system as it gives a professional image and the system is generally treated with greater respect by residents, motorists and users;

- The installation should be accompanied by awareness campaigns and by general incentives for bike usage.

Special attention has been given to the three target 
groups of users, namely the residents, visitors and students.

\section{Locations and Phasing}

The selection of the location of stations (Fig. 5) has encountered various data including: the existing population density, attraction nodes, current and future public transportation, the proposed cycling network for Piraeus, the relevant study for BSS conducted by the Municipality of Athens, European rates (number of bikes/residents and visitors, coverage/housing density, etc.), the origin-destination study conducted by the OECD (Organization for Economic Co-operation and Development) (2006), public consultation results and the available public spaces in close proximity to the main public transportation stations (metro, tram, subway).

The plan describes the development of the BSS stations in four separate phases:

(1) Phase 1 is a pilot implementation which derived from questionnaire results, as part of the public consultation and participation processes. The first 12 stations will be placed in specific areas around the waterfront public spaces, the university and the public transportation stations. An average of 20 bicycles will serve each of the BSS stations, while the stations with a higher provision in demand (such as the ones near the subway station, the stadium and the municipal theatre) will accommodate relatively more vehicles. Phase 1 is planned to accommodate 240 bicycles in 12 stations within close distances and in absolute accordance to the proposed cycling network;

(2) Phase 2 connects more attraction nodes, future transportation stations (i.e., new metro stations), some parks and public squares, and most importantly, the cruise port hinterland zone and the passengers' port zone to the centre. It adds 10 more stations with 20 bicycles for each one of them (200 more bicycles in total) and acts in a complementary way to the first phase;

(3) Following, the Phase 3 covers with 18 more stations in the most central areas and the key neighborhoods of Piraeus with a density of 408 1,573 residents/hectare and 222 408 residents/hectare (Fig. 6). By the end of this phase, Piraeus will have a network of 40 stations with a total

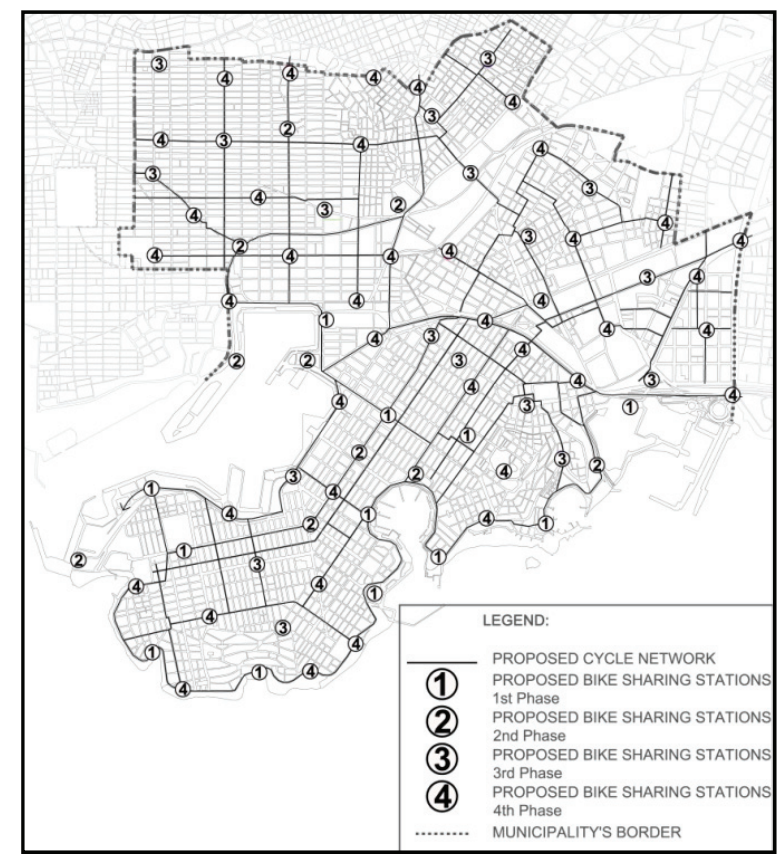

Fig. 5 Indicative locations of the BSS stations.

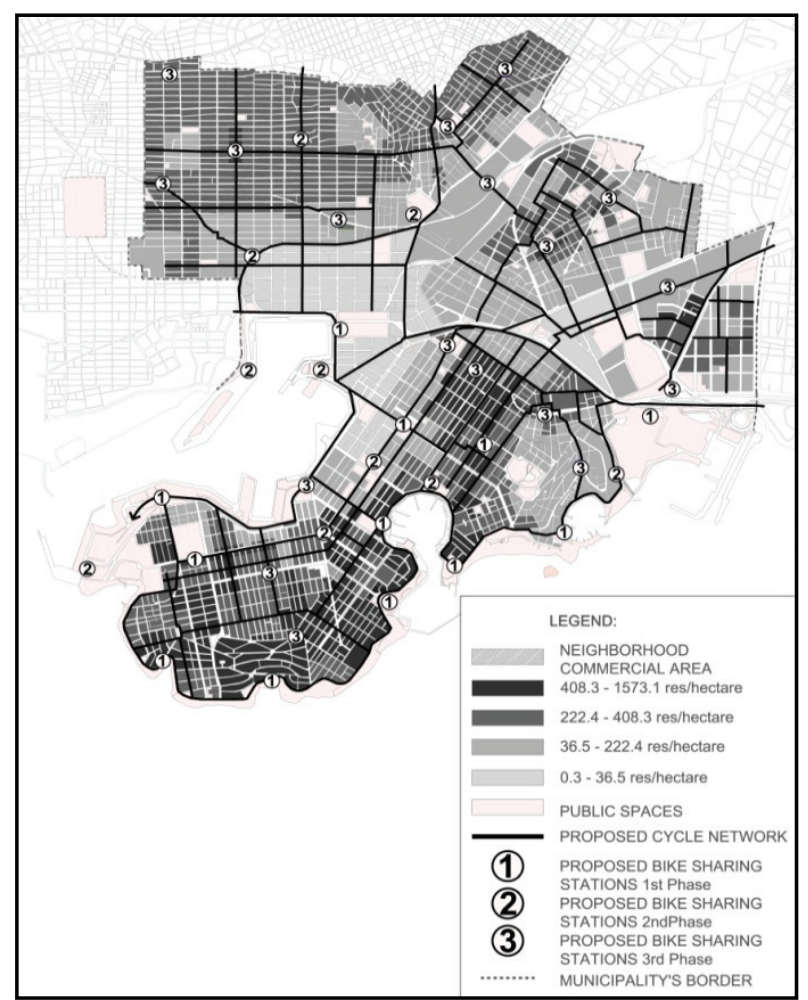

Fig. 6 Third implementation phase of the BSS network. 


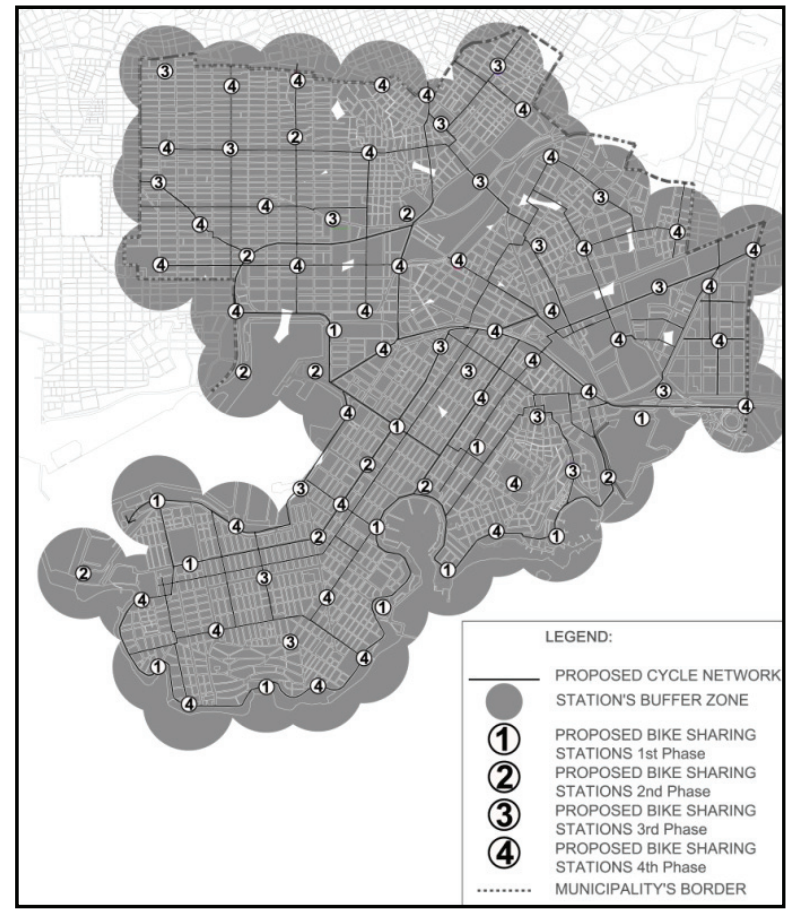

Fig. 7 Fourth implementation phase of the BSS network.

of 800 bicycles;

(4) Lastly, the Phase 4 (Fig. 7) aims to expand and cover the whole surface of the municipality filling the spaces between the aforementioned areas while also following the $250-\mathrm{m}$ radius rule. Eventually, the remaining 40 stations will be placed in the central area and within 250 meters buffer zones from the previous stations as well as close to special land uses (i.e., schools, sport and recreational facilities, shopping areas).

The coverage of the final bike sharing scheme is highly acceptable with a total of 80 stations and 1,600 bicycles (Fig. 7), and it only leaves a few areas without a direct access to stations, though the remaining distances can be covered on foot.

A matter of crucial importance in order for the scheme to be successful is the ensuring of safety for BSS users, which can be achieved through low cost measures that will decrease traffic speeds and prioritize pedestrians and cyclists. Horizontal and vertical signaling along with traffic bumps will assist the information of drivers for the cyclists' presence and information signals will be located in several areas around the municipality to inform about the location of stations, the distance among them, costs and indicative routes to be followed.

The software provided to operate and support the BSS should be a complete development platform that will allow:

(1) the determination of system's pricing policy;

(2) the connectivity with an online portal for providing information about bicycle availability;

(3) online connection for the update of subscriptions, credit loading, sign up processes for new users, etc.;

(4) real time usage data;

(5) bicycle damage details;

(6) utilization statistics;

(7) users' data;

(8) malfunction nodes.

\section{Conclusions}

Dealing with major environmental causes like climate change as well as with the daily problems (congestion, car-dependency, accidents, etc.), Piraeus is at a critical point where major public transportation infrastructure are introduced and has an aspiring plan that sets out different priorities in transportation and mobility habits. Cycling has strategic importance for the mobility management schemes and the sustainable development of European cities [1]. The active involvement of Piraeus Municipality in CycleCities Project has engaged it to good practices for cycling integration into urban mobility management schemes among European cities. In the European urban transport discourse, cycling is now at the cutting edge.

Thus, the deficiencies of the Greek planning system are particularly acute, meaning that applying sustainable mobility management schemes from scratch seemed, for years, far from realistic in terms of measures and infrastructure building due to a number of reasons. The role of local authorities and policymakers is crucial in identifying the issues and implementing sustainable mobility plans that could 
alter the image of the cities and relieve the urban environment. Most importantly, citizens need to be convinced and endorse such policies, which can only be achieved after excessive consultation and as part of an overall awareness raising campaign. The methodology proposed fits to inexperienced municipalities with little or no precedents in alternative mobility applications.

This study has identified the main intervention areas in order to implement a coherent sustainable urban mobility plan for the Municipality of Piraeus which included the following:

- creating low traffic/traffic calmed areas;

- creating green corridors;

- creating a pedestrian network;

- suggestions for traffic management;

- suggestions for the cycling network;

- linking Piraeus with the surroundings;

- tram extension;

- new bus lines;

- suggestions for further information and awareness.

The paper has focused mostly on the development of the cycling network as well as the design of a four-phased bike sharing system. In order for such a plan to be successful, the three critical stages, namely the implementation of infrastructure, the organization of the municipality and the information, communication and public awareness, have been examined briefly. However, it should be noted that the stage of information-communication-public awareness requires a sufficient timetable, which in the case of Piraeus was limited to four months. Consequently, procedures were forced to fit in a tight plan, questioning its future acceptance.

Piraeus is changing into a strong transportation hub due to metro and tram network extension. The time is critical and the challenge of the proposed plan can turn the city into an exemplar case of sustainable mobility prototype in the Greek environment. Concluding, Piraeus has signed the Covenant of Mayors committing to increasing energy efficiency and the use of renewable energy sources on its territory. The described plan is in absolute accordance to the covenant's initiatives and suggested policy implementations in terms of sustainable local development.

\section{Acknowledgments}

The research of this paper was funded by the INTERREG IVC Programme under CycleCities Project and the Municipality of Piraeus. Brainbox, S. A. has also participated in the development of the sustainable mobility plan of Piraeus. The scientific director of the project was Prof. Thanos Vlastos.

Some of the main researches that contributed in developing the presented proposals are: Dr. Konstantinos Athanasopoulos, Filyra Vlastou, Trisevgeni Papagerasimou, Vassilis Eleftheriou and Charalampos Kyriakidis.

\section{References}

[1] CycleCities Project. 2014. "CycleCities Project, an Interreg IVC Project." CycleCities Project. Accessed December 12, 2015. http://www.cyclecities.eu/data-en/fi le/cyclecities_Presentation.pdf.

[2] European Environment Agency. 2009. Ensuring Quality of Life in Europe's Cities and Towns. EEA report No. 5.

[3] COM (European Commission). 2013. Communication from the Commission to the European Parliament, the Council, the European Economic and Social Committee and the Committee of the Regions: Together towards Competitive and Resource-Efficient Urban Mobility. COM (2013), 913 final.

[4] WHO (World Health Organization). 2000. The World Health Report 2000-Health Systems: Improving Performance. WHO report.

[5] Vassi, A., Vlastoy, F., Athanasopoulos, K., and Vlastos, T. 2015. "Public Perception of Sustainable Mobility in Times of Austerity-The Case of Piraeus." In Book of Abstracts of the International Conference on Changing Cities II, 553. ISBN: 978-960-6865-85-5.

[6] Hellenic Statistical Authority. 2011. National Statistical Survey of 2011. Piraeus: Hellenic Statistical Authority.

[7] Cambridge Cycling Campaign. 2014. Making Space for Cycling-A Guide for New Developments and Street Renewals. London: Cyclenation.

[8] Department of Communities and Local Government. 2012. "National Planning Policy Framework." Department of 
Communities and Local Government. Accessed December 14, 2015. https://www.gov.uk/government/uploads/syste m/uploads/attachment_data/file/6077/2116950.pdf.

[9] Greater London Authority. 2013. The Mayor's Vision for Cycling in London-An Olympic Legacy for Londoners. London: Greater London Authority.

[10] Newman, P., and Kenworthy, J. 1989. Cities and Automobile Dependence: An International Sourcebook. Aldershot: Gower Publishing.

[11] Milakis, D. 2006. "Land Uses and Transportation. Investigation of the Effect of Micro and Macro Scale Urban Characteristics on Transportation Decisions." Ph.D. thesis, National Technical University of Athens.

[12] National Collaborating Center for Healthy Public Policy. 2011. Urban Traffic Calming and Health-A Literature
Review. Quebec: Institut National de Santé Publique du Québec.

[13] Organization of the Master Plan and Environmental Protection of Athens. 2014. Strategic Plan for Athens-Attica 2021. Athens: Ministry of Environment, Energy and Climate Change.

[14] Shaheen, S., Guzman, S., and Zhang, H. 2010. "Bikesharing in Europe, the Americas, and Asia." Journal of the Transportation Research Board 2143: 159-67.

[15] Midgley, P. 2011. "Bicycle-Sharing Schemes: Enhancing Sustainable Mobility in Urban Areas." Presented at Commission on Sustainable Development Nineteenth Session, New York, USA.

[16] DeMaio, P. 2009. "Bike-Sharing: History, Impacts, Models of Provision, and Future." Journal of Public Transportation 12 (4): 41-56. 